\title{
Artigos
}

\section{Diferença sexual, direitos e identidade: um debate a partir do pensamento da desconstrução*}

\author{
Carla Rodrigues**
}

\begin{abstract}
Resumo
Este artigo aborda a diferença sexual a partir da análise do filósofo Jacques Derrida e seu diálogo com a filosofia de Heidegger e de Emmanuel Levinas, articulando essa questão com a reivindicação de direitos para as mulheres, pensada como forma de superação da hierarquia de gênero implícita na dualidade masculino/feminino e questionada pelo pensamento da desconstrução. O trabalho procura demonstrar as possibilidades de aliança entre o pensamento da desconstrução $e$ as teorias feministas.
\end{abstract}

Palauras-chave: Pós-estruturalismo, Diferença Sexual, Gênero, Jacques Derrida, Teoria Feminista.

\footnotetext{
* Recebido para publicação em dezembro de 2008, aceito em novembro de 2009. Este artigo é parte da minha dissertação de mestrado - O sonho dos incalculáveis - coreografias do feminino e do feminismo a partir de Jacques Derrida -, defendida em março de 2008, no Departamento de Filosofia da PUC-Rio sob orientação de Paulo Cesar Duque-Estrada, a quem agradeço o acolhimento.

** Doutoranda em Filosofia (PUC-Rio), pesquisadora do Núcleo de Estudos em Ética e Desconstrução (NEED/www.need.pro.br), jornalista. carla@puc-rio.br
}

cadernos pagu (34), janeiro-junho de 2010:209-233. 
Diferença sexual, direitos e identidade

Sexual Difference, Rights and Identity:

a Debate arising from the Poststructuralist Theory

\begin{abstract}
The analysis of philosopher Jacques Derrida and his dialog with the philosophy of both Heidegger and Emmanuel Levinas is the starting point for this paper, which presents a discussion about sexual difference, establishing a link between the issues of sexual difference and claim for women's rights as a way to overcome the hierarchy of gender, which is implicit in the feminine/masculine dualism and questioned by deconstruction. This paper attempts to show the possibilities of alliance between deconstruction and feminists theories.
\end{abstract}

Key Words: Deconstruction, Gender, Sexual Difference, Jacques Derrida, Feminist Theory. 
A diferença sexual, pensada de forma opositiva a partir do par masculino/feminino, tem sido uma questão e um problema para a teoria feminista. Com o pensamento da desconstrução, o filósofo Jacques Derrida questionou as oposições binárias e metafísicas, inclusive a que opõe masculino e feminino, abrindo espaço para a interrogação sobre a dualidade dos sexos. ${ }^{1} \mathrm{~A}$ partir do questionamento do que ele chama de "um implacável destino que em tudo perpetua o número dois", Derrida (1992:115) pensa a diferença sexual não subordinada à marca da dualidade, aspecto que será explorado na primeira parte do artigo a partir de um diálogo entre Derrida, Heidegger, Emmanuel Levinas e Elizabeth Grosz. A segunda parte do texto articula a questão da binaridade com as reivindicações de direito, partindo das proposições de equivalência de direitos de Drucilla Cornell, uma das autoras que reconhece a importância de repensar a diferença sexual em termos não-hierárquicos ou duais, de forma a conferir valor ao feminino fora da estrutura patriarcal que mantém o masculino como padrão.

\section{A questão da diferença sexual}

As características e peculiaridades da diferença sexual foram discutidas por Jacques Derrida principalmente a partir de sua leitura de Heidegger, filósofo que, para Derrida, considerava que a diferença sexual deveria ser tratada como antropológica, sociológica ou biológica por não estar "à altura" da diferença ontológica. No pensamento heideggeriano, a diferença ontológica - que distingue ser e entre - aparece como a diferença mais significativa, acima de qualquer outro conceito ou instância de diferenças.

Derrida pontua o fato de Heidegger ter guardado silêncio sobre a diferença sexual, um silêncio que motiva sua operação

\footnotetext{
1 Ver a entrevista Derrida com a feminista Christie V. McDonald em Chorégraphies.
} 
Diferença sexual, direitos e identidade

de buscar o que há de tão simbólico no que ele classifica como "omissão, recalque, denegação, forclusão" em Heidegger (Derrida, 1990:149). Derrida se refere especificamente ao segundo parágrafo de Ser e tempo, quando Heiddeger (2002:30) define a estrutura formal da questão do ser, mas se omite em relação à diferença sexual.

À princípio, Derrida está interessado em demonstrar que o Dasein $^{2}$ é uma construção heideggeriana cuja escolha como "ente exemplar" se dá em forma de "decreto" (Derrida, 1990:151). A neutralidade do Dasein aparece como uma maneira de não conferir a ele nenhum tipo de pré-determinação "antropológica, ética ou metafísica". Em suas palavras,

A neutralidade é portanto o primeiro lugar da neutralização de tudo que não é o traço nu da relação à si, desse interesse por seu ser próprio no sentido mais amplo da palavra "interesse". Isso implica um interesse ou uma abertura pré-compreensiva ao sentido do ser $e$ às questões que ele impõe (Id.ib.:152). ${ }^{3}$

O autor chama a atenção para o fato de que, em Heidegger, essa neutralidade passa muito rapidamente a ser neutralidade sexual ou assexualidade. O filósofo lembra que, em Heidegger, essa neutralidade do Dasein aparece como "essencial", como um traço do ente. Ao se concretizar, o ente deverá pertencer a um dos dois sexos. O Dasein é neutro e, Derrida pontua, Heidegger não tem nenhuma dúvida de que, quando adquire a marca sexual, essas marcas são duas. A dualidade aparecerá como uma questão para Derrida porque,

2 Dasein é o termo usado por Heidegger para se referir aos seres humanos. Comumente traduzido por ser-aí, o Dasein tem como estrutura primordial a possibilidade de ser, ou seja, não é ser algo definível previamente, e está desde sempre lançado nesse "aí" (Inwood, 2002).

3 Todos os trechos de obras em língua estrangeira foram traduzidos por mim. 
Carla Rodrigues

se o Dasein não é neutro e se ele não é o homem, a primeira conseqüência a tirar é que ele não se submete à divisão binária com a qual se pensa mais espontaneamente, nesse caso, a diferença sexual (Id.ib.:153).

Derrida argumenta que se o Dasein não significa o homem, também não significa, a princípio, nem o homem nem a mulher. $\mathrm{O}$ que Heidegger trata como a negatividade da neutralidade do Dasein, para Derrida será uma positividade da qual nem mesmo Heidegger se deu conta.

Se o Dasein não pertence a nenhum dos dois sexos, isso não significa que o ente seja privado de sexo. Ao contrário, se pode pensar aqui em uma sexualidade prédiferencial, ou antes, pré-dual, o que não significa unitária, homogênea, indiferente (Id.ib.:156).

O filósofo estaria, assim, pensando na potencialidade de uma sexualidade pré-dual, anterior à disseminação factual do ente, que ele compara à positividade do desvelamento (aletheia):

Dasein em geral esconde, participa em si da possibilidade interna de uma dispersão ou de uma disseminação factual no seu corpo próprio e na sexualidade. Todo corpo próprio é sexuado e não há Dasein sem corpo próprio. Mas a ligação proposta por Heidegger parece muito clara: a multiplicidade dispersante não tem início com a sexualidade do corpo próprio, é o corpo próprio, ele mesmo, a carne, a corporalidade [leiblichkeit] que participa originariamente do Dasein na dispersão e, por conseqüência, na diferença sexual (Id.ib.:161).

Derrida chama a atenção para a expressão "por conseqüencia", recorrente no texto heideggeriano como uma 
Diferença sexual, direitos e identidade

forma de demonstrar que o Dasein deveria ter ou ser "a priori um corpo que se encontra sexuado e afetado pela divisão sexual" (Id.ib.:161). O autor também problematiza a negatividade heideggeeriana, ao afirmar que o Dasein, estando submetido a um corpo, está submetido a uma divisão em direção à sexualidade, em direção a um sexo determinado. A negatividade que aparece em diversos termos empregados no texto de Heidegger (dispersão, divisão, dissociação) esconderiam, para Derrida, a positividade e a potência que também aparecem na idéia de disseminação originária ou de dispersão transcendental que Heidegger confere ao Dasein.

Se deveria, portanto, dizer que nenhuma significação negativa está ontologicamente ligada ao neutro em geral, nem, sobretudo, a essa dispersão transcendental do Dasein (Id.ib.:169).

Elizabeth Grosz aponta que a questão do status ontológico da diferença sexual é uma das mais centrais à teoria feminista atual. Para ela, na leitura que Derrida faz de Heidegger há um distanciamento em relação ao modelo binário da sexualidade. Essa distância faria Derrida caminhar em direção à neutralização do Dasein (Grosz, 1997:88). Segundo a autora, Derrida estaria reivindicando uma sexualidade mais primordial do que a da oposição binária entre os sexos, uma diferença sexual que é neutra em relação a ambos os sexos, a "matéria-prima" a partir da qual, através da dispersão e da dissociação, a diferença sexual se torna concreta e específica. "Esta sexualidade primordial é, por assim dizer, Dasein, uma ordem sexual anterior à determinação que é em si sexual" (Id.ib.:89).

Grosz argumenta ainda que Heidegger parece estar comprometido com duas posições de difícil conciliação: de um lado, o filósofo alemão insistiria na neutralidade do termo Dasein. De outro, ao fazer do Dasein a origem das coisas, da existência concreta, inclusive da existência humana, Heidegger 
estaria concordando que há no Dasein uma abertura à especificidade sexual. Nas palavras da autora,

Há, por um lado, o endividamento [indebtedness] da oposição sexual a um neutro, o Dasein; por outro lado, o Dasein é o estado primordial da sexualidade antes da sua determinação em forma concreta (Id.ib.:89).

Após explorar essa dupla postura heideggeriana, Grosz afirma que o Dasein contém sua própria possibilidade de dispersão e de multiplicidade, incluindo a aquisição de diversas qualidades, como a especificidade sexual. O Dasein seria, assim, na compreensão de Grosz, a condição de possibilidade de determinação sexual. Na sua leitura de Derrida, Grosz afirma que ele sugere que o Dasein não é simplesmente neutro, sem vestígios de marca sexual, mas que "neutraliza qualquer marca sexual prévia". Derrida estaria indicando que não existe, na estrutura do Dasein, um predicado propriamente sexual.

A partir da leitura sobre a diferença sexual em Heidegger, Derrida problematiza a dualidade da diferença sexual, quando diz que Heidegger neutraliza não a sexualidade "ela mesma", mas a marca genérica da diferença sexual, o pertencimento a um dos dois sexos. Nas palavras de Derrida,

A partir daí, tomando de volta a dispersão $e$ a multiplicação, não se pode começar a pensar numa diferença sexual (sem negatividade, precisemos) que não seria selada pelo dois? (Derrida, 1990:172).

Em Chorégraphies, Derrida volta ao tema da diferença sexual em Heidegger para afirmar que o Dasein

não carrega as marcas dessa oposição ou dessa alternativa entre um ou outro dos dois sexos. Essas 
Diferença sexual, direitos e identidade

marcas não são das estruturas essenciais, nem ao menos marcas opostas ou binárias (Derrida, 1992:111).

Dito de outro modo, se o Dasein contém a condição de possibilidade de determinação sexual, se ele não é neutro, e se não há no Dasein um predicado sexual, Derrida pergunta: porque o Dasein precisa estar selado pelo número dois? Ou ainda, porque restringir a positividade do Dasein a uma estrutura binária e opositiva? Ana Maria Continentino sintetiza a questão da diferença sexual nos termos derrianos, ao sinalizar que a neutralização exige pensar a diferença sexual em outro nível:

Ele [Derrida] destina o Dasein a uma diferença e a um sexual que é abertura para uma outra dimensão, uma outra ordem que resiste às oposições, sustentando-as. Dimensão que positiva o sexual como interesse, até mesmo como interesse mais radical, fonte de toda sexualidade possível (Continentino, 2001:34).

A autora toca numa das questões que me interessa: a possibilidade de pensar para além da estrutura binária do par opositivo feminino/masculino. Nessa reflexão sobre a abertura a múltiplas coreografias, está pressuposta uma discussão sobre a abertura dos limites da metafísica, tema que aparece em Derrida quando ele encerra Chorégraphies, defendendo a mulher pensada como indecidível, como fora da lógica da oposição binária, como aquela que vai abrir espaço para os incalculáveis sexos:

Não é impossível que o desejo de uma sexualidade incalculável venha ainda nos proteger, como um sonho, contra um implacável destino que em tudo perpetua o número dois (Derrida, 1992:115).

John Caputo explora o fato de Derrida encerrar Chorégraphies sonhando com uma dança, com o improviso, 
com a criação de novos passos e movimentos, novos estilos. $\mathrm{Na}$ leitura de Caputo, Derrida

sonha com a "dança", a "coreografia", para recolocar e deslocar o primado "topográfico", a coreografia que não esteja misturada com "troca" de lugares, mas uma coreografia que improvise, crie novos passos, novos movimentos, novas danças, novos estilos, que invente novas e inéditas combinações e mutações. Ele sonha com as "coreografias incalculáveis" (Caputo, 1997:156).

Assim, Caputo afirma que nem o homem nem a mulher estão vindo nesse "sonho" - nem isto, nem aquilo, mas uma bem-vinda indecidibilidade. Embora reconheça que pode soar "impossível" pensar para além de dois gêneros, insiste no incalculável:

Talvez o que esteja por vir não seja tão simples e nãoambíguo como um hermafrodita ou um andrógino, mas alguma coisa indecidível e miscigenada, que não aconteceu ainda, alguma coisa singular, algo possível, algo impossível, alguma coisa inimaginável e incalculável (Id.ib.:157).

Caputo afirma ainda que, em relação à diferença sexual, o sonho de Derrida é uma "sexualidade sem número", não marcada por sexos opostos ou oposições identificáveis, não selada com duas classificações opostas, homem e mulher, não submetida à classificação da lei do gênero (Id.ib.:156).

Grosz também estabelece um diálogo com Derrida sobre diferença sexual a partir da leitura de At this very moment in this work here I am, texto em Derrida formula duas perguntas: 1) o 
Diferença sexual, direitos e identidade

totalmente outro ${ }^{4}$ de Levinas estaria além ou antes da determinação sexual? 2) ou, ao contrário, a determinação sexual é parte do conceito de totalmente outro, tomando esse outro como feminino?

Em primeiro lugar, ela reconhece a importância de Levinas ter assumido que escreve como homem. Um reconhecimento que aparece em Derrida, quando ele diz que há na escrita levinasiana uma "assinatura masculina" que romperia com a associação tradicional entre neutralidade $e$ masculino. Mas Grosz também enxerga, na leitura que Derrida faz do pensamento de Levinas, um tratamento secundário ao tema da diferença sexual. De At this very moment in this work here I am ela destaca a seguinte passagem:

O trabalho de Emmanuel Levinas me parece sempre ter deixado como secundário, derivativo e subordinado a alteridade como diferença sexual, o traço da diferença sexual, para a alteridade da sexualidade não marcada pelo totalmente outro (Derrida apud Grosz, 1997:90).

Não é a mulher ou o feminino que é tornado secundário, derivado ou subordinado, mas a diferença sexual (Derrida, 1991:40).

Adicionei o trecho em negrito porque me pareceu relevante mostrar que, a partir deste ponto, Derrida discutirá outro aspecto do pensamento de Levinas: a secundarização da diferença sexual, que ficaria subordinada à marca do masculino.

4 Em texto dedicado a Emmanuel Levinas, Derrida (2004) homenageia o amigo ao afirmar que o pensamento do filósofo teria sido, para ele, fonte de grande inspiração. Derrida afirma ainda que Levinas mudou o curso da filosofia contemporânea com o pensamento do outro. Essa idéia do totalmente outro - expressão que Derrida incorpora no vocabulário da desconstrução e na sua formulação de singularidade - propõe o reconhecimento da "dissimetria absoluta" em relação ao outro. Cornell (1992a) reconhece a influência da obra de Levinas no pensamento de Derrida e também dialoga com essa proposição levinasiana do totalmente outro. 
A questão também será problematizada por McDonald em Chorégraphies: o filósofo lituano se alinharia à tradição de secundarização da mulher quando apresenta a sexualidade masculina como uma "origem neutra ou ao menos anterior $e$ superior a toda marca sexual"? (Derrida, 1992:109). Derrida se pergunta ainda: como a marca masculina poderia ser anterior à diferença sexual?

Para discutir esse aspecto do pensamento de Levinas, Derrida (1991:41) cita passagens de dois textos do filósofo: Judaism and the feminine e de Et Dieu créa la femme:

O sentido do feminino será esclarecido tomando como ponto de partida a essência humana, o Ischa como seqüência do Isch: não o feminino como seqüência do masculino, mas a divisão - a dicotomia - entre masculino $e$ feminino na seqüencia do homem. (...) O problema, em cada uma das linhas que estamos comentando, é que na hipótese de uma espiritualidade do masculino, o feminino não seja seu correlativo mas seu corolário; a especificidade feminina ou a diferença entre os sexos que se anuncia não são imediatamente situadas na altura do oposições constitutivas do Espírito. Audaciosa pergunta: como pode a equivalência dos sexos proceder de uma propriedade masculina? Teria que haver uma diferença que não comprometesse a equidade, a diferença sexual; $e$, conseqüentemente, uma certa pré-eminência do homem, a mulher chegou mais tarde e como um apêndice ao humano (Levinas apud Derrida 1977:134).

A partir desse trecho de Levinas, citado por Derrida, observo que, tanto no diálogo com McDonald como na leitura de Grosz, a pergunta formulada por Derrida é de interesse da teoria feminista: "Como se pode caracterizar como masculino o que é considerado anterior, ou mesmo estrangeiro, à diferença sexual?" (Derrida apud Grosz, 1997:90). 
Diferença sexual, direitos e identidade

Essa marca do masculino como anterior à diferença sexual comprometeria o neutro em direção ao privilégio do masculino, já que a humanidade em geral, antes da divisão em dois sexos, seria masculina, e só com o advento posterior da diferença sexual é que viria a mulher (Grosz, 1997:91).

O texto que Grosz discute, At this very moment in this work here I am, foi editado pela primeira vez em francês em 1980 sob o título En ce moment même dans cet ouvrage me voici. Em 1996, por ocasião da morte de Levinas, Derrida publicou $A$ palavra acolhimento, em que ele volta a discutir a questão do feminino na obra do filósofo lituano. Nesse texto, Derrida demonstra que, ao associar acolhimento ao feminino, Levinas poderia estar apresentando uma abordagem "tradicional e androcêntrica" ou, ao contrário, a mesma proposição levinasiana poderia ser lida como um "manifesto feminista" (Derrida, 2004:60). Derrida cita um trecho da obra de Levinas para demonstrar que as duas leituras, embora opostas, são cabíveis:

a casa que fundamenta a posse não é posse no mesmo sentido que as coisas móveis, que ela pode recolher $e$ guardar. É possuída, porque ela é, desde logo, hospitaleira para o seu proprietário; o que nos remete para a sua interioridade essencial e para o habitante que a habita antes de todo habitante, para o acolhedor por excelência, para o acolhedor em si - para o ser feminino (Levinas apud Derrida, 2004:60 [grifos no original]).

Derrida mostra que o pensamento do acolhimento estaria, em Levinas, necessariamente marcado pela diferença sexual - já não mais neutralizada, como nos textos anteriores -, e que esse acolhimento originário seria, "por excelência", feminino.

Geoffrey Bennington aponta que, mesmo quando Derrida demonstra que, muitas vezes, o pensamento de Levinas associa ao feminino uma série de características ligadas à tradição metafísica, ele se interessa pelo alinhamento levinasiano entre o 
feminino e a abertura ética. Mas feminino, aqui, lembra Bennington, não pode ser tomado como um atributo exclusivo das mulheres, mas sim como um espaço que precederia, de algum modo, a diferenciação entre masculino e feminino:

\begin{abstract}
pensar que se isso deve ser chamado de feminino, deve sê-lo no sentido que precede a oposição entre masculino e feminino (pelo menos quando se pensa em termos das oposições tradicionais), ou seja, eticamente pré-originário, mas também feminino pré-originariamente (Bennington, 2004:233).
\end{abstract}

Um dos objetivos deste texto é demonstrar que Derrida problematiza a questão da neutralidade sexual, tal qual ela aparece em Heidegger e Levinas, porque determinadas suposições de neutralidade podem conter uma associação entre masculino e neutro e subordinar o feminino numa oposição binária e hierárquica. Com essa discussão, Grosz argumenta que Derrida está interessado em interrogar sob que condições vem sendo atribuído à mulher um status social secundário baseado na biologia, na natureza e nas qualidades essenciais do feminino. Segundo a autora, Derrida está sugerindo que há uma indeterminação da sexualidade antes da instituição da diferença sexual (Grosz, 1997:93), o que considero uma importante indicação da validade da aliança entre a teoria da desconstrução e a teoria feminista.

\title{
A questão dos direitos e da identidade
}

Um dos aspectos importantes dessa aliança é discutido por Drucilla Cornell e diz respeito ao modo como Derrida pensa a hierarquia de gênero - não apenas como falsa, mas como antiética (Cornell, 1992a:175). Na leitura que Cornell faz de Chorégraphies, ela defende que, na formulação derridiana da radicalidade da alteridade do todo outro, está a chance de uma "nova configuração ética" (Id.ib.:170). A autora argumenta que, 
Diferença sexual, direitos e identidade

ao defender que o privilégio masculino está baseado na fantasia de que ter um pênis é ter um falo, Derrida ${ }^{5}$ toma uma posição ética e política em relação à hierarquia de gênero $e$ indica que essa hierarquia - e a heterossexualidade dela decorrente - é ideológica. Para a autora,

Derrida nos mostra que o falo assume o significado como a metáfora para o que a mãe deseja. Já que a ereção do falo como o significante transcendental baseia-se numa leitura, o significado simbólico do falo pode ser reinterpretado. Assim, a descoberta da diferença sexual anatômica também pode ser reinterpretada (se o falo não for lido pela projeção da fantasia do que significa ter um pênis). Como resultado, a divisão em dois sexos, que é também a base da divisão em heterossexualidade e em homossexualidade, pode aceitar outras interpretações (Id.ib.:175).

Segundo a autora, uma das importantes contribuições do pensamento da desconstrução à política e à teoria feminista está no fato de que a desconstrução considera a diferença sexual como uma questão "crucial" no debate sobre ética. Derrida formula três questões que ilustram sua contribuição nesta direção:

Que tipo de ética haveria se pertencer a um ou outro sexo se tornasse um direito ou um privilégio? E se a universalidade das leis morais fosse modelada ou limitada conforme os sexos? E se a universalidade não fosse incondicional, sem condição sexual em particular? (Derrida, 1992:109).

5 Cornell se refere a inúmeros textos de Derrida dedicados ao diálogo com a obra de Freud e Lacan, nos quais Derrida demonstrar a adesão entre o phallus e o pênis. 
Levar em conta a diferença sexual na determinação de direitos é uma questão pertinente tanto à teoria quanto à política feminista. Grosz pontua que Derrida não oferece soluções, nem ao feminismo nem a nenhum outro tipo de política, uma atitude que costuma provocar suspeitas e percepções de que seu trabalho seria "não-político ou apolítico" ou alinhado a forças conservadoras. O que dificilmente é reconhecido, diz Grosz, são as intenções do pensamento da desconstrução: ao mesmo tempo em que pretende repensar os caminhos sobre os quais a política tem sido feita, não pretende criar uma nova forma de fazer política, mas "reorganizar, ou talvez desorganizar" os caminhos pelos quais as formas de fazer política vêm sendo compreendidas. Nesse contexto, chama a atenção o fato de Derrida considerar que as reivindicações feministas não se resolvem apenas com a aquisição de certos direitos.

Me alinho aos esforços de Caputo, que são coerentes com os de Cornell. Ambos afirmam que o pensamento da desconstrução tem algo a dizer sobre a política feminista $e$ apresentam argumentos para justificar a aliança entre desconstrução e feminismo. Cornell reconhece que há tensões entre feministas e desconstrução, haja vista que as críticas de Derrida ao sujeito estável do feminismo não foram bem aceitas por algumas teóricas feministas, ainda que autoras como Judith Butler, Gayatri Spivak e Chantal Mouffe tenham levado adiante as reflexões $e$ as possibilidades de aliança entre o pensamento da desconstrução e a política feminista. ${ }^{6}$

6 Para exemplificar algumas dessas reações, Cornell cita a expressão de Seyla Benhabib, para quem a aliança entre feminismo e desconstrução "não é fácil". Diane Elam elenca reações de diferentes pensadoras que expressam o "pânico feminista" diante da idéia da desconstrução da categoria do sujeito estável da tradição. Entre os exemplos de Elam está a reação de Margaret Whitford, emblemática de um desejo de unidade totalizante, contrária a qualquer aceitação da idéia de contaminação e fragmentação: "[a desconstrução do sujeito] deixa as mulheres em estado de fragmentação e disseminação que reproduz e perpetua a violência patriarcal que aparta as mulheres" (Whitford apud Elam, 1994:71). 
Diferença sexual, direitos e identidade

Cornell também considera que uma das importantes contribuições do pensamento da desconstrução à política e à teoria feminista está no fato de que a desconstrução considera a diferença sexual como questão "crucial" no debate sobre ética. Derrida questionou a hierarquia de gênero ao problematizar a divisão binária masculino/feminino, mostrando como essa é mais uma oposição convencional sustentada por uma hierarquia que toma o masculino como universal.

Cornell destaca que entre as possibilidades de aliança entre feminismo e desconstrução está o fato de que, para Derrida, é precisamente a possibilidade de reinterpretação do feminino que oferece às mulheres a esperança de não serem para sempre aprisionadas em papéis de gênero que, embora muitas vezes pareçam "libertadores", também correm o risco de funcionar, segundo Derrida, como "novas determinações topográficas". Com essa expressão, ele questiona as reivindicações feministas de encontrar um lugar para a mulher:

A senhora [McDonald] não teme que uma vez engajada no caminho dessa topografia nós nos reencontremos forçosamente de volta ao "em casa ou na cozinha", ou na direção das prisões domiciliares, como se diz em francês na linguagem penitenciária - o que finalmente daria no mesmo? Por que seria necessário que houvesse um lugar para a mulher? E por que um só, um essencial? (Derrida, 1992a:99).

Na leitura de Chorégraphies, Cornell lembra que Derrida demonstra não querer que o feminismo seja "outra desculpa para um desfile de carteiras de identidade sexual" (Cornell, 1999:87). Segundo ela, ao defender a não-identidade da mulher, Derrida tem sido acusado de reafirmar as estruturas hierárquicas da sociedade patriarcal, na qual a mulher não teria identidade por só poder ser pensada como o Outro do homem, o que faria da desconstrução "apenas o disfarce do pior aspecto do patriarcado" (Cornell, 1999:102). 
O diálogo de Cornell com Derrida passa também pela compreensão de que, para o filósofo, a "desconstrução é um chamado à justiça". Cornell trabalha com essa hipótese, recuperando a idéia de que, no pensamento da desconstrução, a justiça é um chamado do Outro. Nessa concepção de justiça, ela retoma as afirmações de Derrida e lembra que "eqüidade não é igualdade, a proporcionalidade calculada, a distribuição eqüitativa, mas, ao contrário, a infinita demanda do chamado do Outro" (Derrida apud Cornell, 1999:113).

Para interrogar a universalidade do masculino, a autora faz uma distinção entre direitos iguais e equivalência de direitos, não em termos de uma disjuntiva, mas de um deslocamento da idéia de busca pela igualdade, que se mostraria inútil na eliminação das desigualdades entre homens e mulheres, na medida em que toma o masculino como norma. Direitos iguais aos dos homens seriam, para ela, apenas uma forma de manter o masculino como superior ao feminino. Para Cornell, os direitos das mulheres não podem estar relacionados às normas que a cultura impõe à feminilidade (Cornell, 1998), porque estariam limitados a essas características e se baseariam na diferença sexual como justificativa para a subordinação e para a exclusão da mulher. Em outras palavras, Cornell aponta para o fato de que pensar a igualdade é ignorar a injustiça constitutiva da polaridade homem/mulher e, por conseqüencia, contribuir para sua manutenção.

Assim, a autora defende como tarefa crucial para uma aliança entre desconstrução e feminismo não endossar uma concepção de justiça que aprisione as mulheres. Cornell defende, assim, uma obrigação masculina de se endereçar diretamente às mulheres - "the rectitute of adress" - não como uma "resposta paternalista à incapacidade de falar em seu discurso" (Cornell, 1999:115), mas pela obrigação de ouvir o chamado das mulheres.

"Por que é 'justo' tomar os homens como o padrão, com exceção do fato de que tem sido sempre assim e, por isso, o 
Diferença sexual, direitos e identidade

custo é menor?" (Id.ib.:113). Ela afirma que a redução da justiça à proporcionalidade do cálculo torna impossível pensar em justiça para mulheres enquanto as medidas forem masculinas. Por isso, defende que só agora está sendo possível "ouvir e ler" uma linguagem feminina, e que essa linguagem feminina deverá criar no homem "uma obrigação" de ler a linguagem feminina $e$ suas interpretações. ${ }^{7}$ Para ela, os direitos das mulheres não podem estar relacionados às normas que a cultura impõe à feminilidade (Cornell, 1998:21), porque estariam limitados a essas características e manteriam a utilização das diferenças como justificativa para a subordinação.

Na proposição de Cornell sobre a equivalência de direitos, o masculino deixaria de ser tomado como referência. Essa noção de equivalência de direitos é pensada como caminho para a aceitação do direito de escolha de diferentes maneiras de viver (Cornell, 1992b). Segundo a autora, para que essa liberdade se dê, seria preciso reconhecer a legitimidade dos relacionamentos íntimos não-tradicionais e conferir valor ao feminino na diferença sexual ${ }^{8}$ :

7 Cornell pensa essa "obrigação dos homens" como uma das etapas de um processo antes do que Robin West chama de "reconstrução de uma jurisprudência feminina". West é uma das autoras com as quais Drucilla Cornell está dialogando sobre o que nos EUA se chama de "teoria jurídica feminista". Os dois textos citados por Cornell como referências para esse debate são Robin West. Jurisprudence and gender. University of Chicago Law Review, vol. 55, n 1, 1988 [parcialmente disponível em http://links.jstor.org] e The difference in Women's Hedonics Lives: a phenomenological critique of feminist legal theory. Wisconsin Law Journal, vol. 3, 1987.

8 Cornell se refere particularmente aos arranjos homossexuais em proposições amplas, que não caberiam neste trabalho. Apenas pontuo que elas se articulam com o tema da equivalência de direitos quando Cornell defende a idéia de que o reconhecimento de direitos equivalentes para os homossexuais equivaleria ao reconhecimento das especificidades. Para Cornell, não se poderia justificar tratamento desigual perante a lei aos homossexuais por eles terem um relacionamento não-heterossexual, tomado como norma. A mesma lógica valeria para a discussão sobre o reconhecimento das especificidades da 
Carla Rodrigues

Estes direitos exigem a aceitação de um compromisso fundamental, talvez a premissa mais básica do feminismo: a de que aquilo que inúmeras vezes na cultura patriarcal chama-se humano é o sexo masculino, o que implicitamente apaga o outro gênero da espécie humana: o feminino (Cornell, 1992b:281).

A autora evoca a necessidade de pensar a "mulher" além da oposição binária entre masculino e feminino, como forma de "resistir à lógica da identidade reproduzida na hierarquia de gênero" (Cornell, 1999:118). Ela quer valorizar o feminino dentro da diferença sexual e, para isso, propõe um duplo trabalho: evitar a cumplicidade com os mecanismos da sociedade patriarcal que tomam o masculino como padrão e, ao mesmo tempo, romper com a afirmação da identidade sexual. Para Cornell, sustentar uma diferença sexual opositiva seria contribuir para sustentar o feminino no lugar secundário ou subordinado. Nesse sentido, não seria simplesmente abrir espaço para as mulheres no "mundo masculino", mas discutir a discriminação contra a mulher, que para ela não pode ser definida a partir de uma comparação entre homens e mulheres. ${ }^{9}$

Seguindo o pensamento de Derrida, Cornell chega à discussão da associação entre neutralidade e masculino, que assume o homem como norma, estabelecendo a hierarquia de gênero que mantém as mulheres em estado de "negligência", no qual o feminino é "ignorado, repudiado e limitado por estereótipos" (Cornell 1992b:292). Como diz Cornell,

A luta política contra a negligência, em nome da igualdade de bem-estar [entre homens e mulheres],

mulher, que não podem ter tratamento desigual perante a lei por não serem homens, tomados como norma.

9 Sobre as proposições de Cornell para equivalência de direitos entre homens e mulheres e discriminação remeto ao artigo "Da igualdade à equivalência: o caso Sears 30 anos depois" (Rodrigues, 2009). 
Diferença sexual, direitos e identidade

envolve o reconhecimento da diferença feminina nas circunstâncias em que somos diferentes, como na nossa relação com a gravidez, enquanto simultaneamente não reforça os estereótipos através dos quais o patriarcado tem tentado fazer sentido com que a diferença limite nosso poder (Id. ib.:293).

Cornell não quer tomar o masculino como padrão por acreditar que isso serviria para legitimar a concepção de que os direitos, tal qual foram formulados pelos homens, seriam a norma e o modelo a ser alcançado. As idéias de Cornell fizeram eco, por exemplo, no pensamento de Diane Elam, para quem a equivalência de direitos - em substituição aos direitos iguais seria uma forma de reconhecer categorias de direitos que não estariam contempladas na idéia de direitos iguais. Elam problematiza a proposição de Cornell, segundo a qual a equivalência de direitos - em substituição aos direitos iguais seria uma forma de reconhecer categorias de direitos que não estariam contemplados na idéia de direitos iguais. Elam discute a questão da equivalência de direitos apresentada por Cornell ao questionar a validade da reivindicação de direitos tomando os homens como se "fossem os únicos gêneros da espécie humana" (Id. ib.:281).

Elam lembra que na concepção tradicional de política, antes que se reivindiquem direitos específicos, é preciso supor a existência de um sujeito político. Assim, o sujeito político seria instituído primeiro, para que depois o direito desse sujeito fosse conquistado. Mas, argumenta ela, se o pensamento da desconstrução considera que os sujeitos políticos são provisórios, esse pensamento passa a prestar atenção na forma pela qual cada direito institui o sujeito político a quem tal direito é atribuído. Para Elam, a aliança entre desconstrução e feminismo requer a discussão da questão dos direitos a partir de outra pergunta: que direitos pertencem a quais sujeitos? Para ela, a partir do momento em que o pensamento da desconstrução 
desloca a idéia de direito como uma propriedade dos sujeitos, modificam-se os critérios para determinar os "direitos". Assim, a autora argumenta que

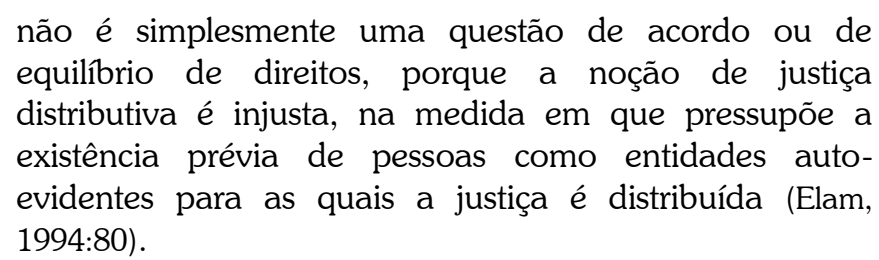

Embora endosse a proposição de equivalência de direitos de Cornell como uma "posição estratégica útil", Elam argumenta que essa idéia não ofereceria uma forma de avançar para além da política baseada no sujeito estável e identificável (Id.ib.:77). Em outras palavras, a autora está interessada em articular a questão da equivalência de direitos a que se refere Cornell com a questão da mulher como "sujeito de direitos", de tal forma que a política não seja pensada apenas como reivindicação identitária.

Apesar dessas diferenças, as duas autoras inscrevem a diferença sexual como critério importante na reivindicação dos direitos, sem que se tome essa diferença para manter as mulheres presas a uma hierarquia de gênero que privilegia o masculino ou em busca de um tipo de "libertação" que toma o masculino como norma.

\section{Considerações finais}

O aspecto que busquei articular nas duas partes deste artigo parte da associação entre o status de problema filosófico que a desconstrução confere à diferença sexual e sua articulação com a questão dos direitos, questão que Cornell defende ao apontar que a aliança entre a desconstrução e o feminismo oferece a possibilidade de uma "descoberta da especificidade 
Diferença sexual, direitos e identidade

feminina", permitindo ver o gênero feminino de um modo "realmente diferente" (Cornell, 1999:117):

O pensamento da diferença sexual não pode ser reduzido a questões políticas ou jurídicas em termos de "direitos das mulheres". Pensar a "Mulher" além da oposição é resistir à lógica da identidade reproduzida na hierarquia de gênero (Id.ib.:118).

A autora lembra que Derrida sempre faz distinção entre o sonho de uma nova coreografia da diferença sexual, que não pode ser apagada, e a realidade do sistema de opressão à mulher. Para Cornell, o importante não é valorizar apenas a possibilidade de uma nova coreografia da diferença sexual, mas valorizar o feminino dentro da estrutura da diferença sexual.

Diferentemente de Françoise Collin ${ }^{10}$, que entende o deslocamento da identidade sexual, tal como proposto pelo pensamento da desconstrução, como uma aliança com o patriarcado, Cornell apresenta uma proposição de dupla postura que repete o gesto derridiano de invocar um duplo trabalho para o feminismo. Seguindo uma proposição muito presente em Derrida, Cornell propõe ao mesmo tempo evitar a cumplicidade com os mecanismos da sociedade patriarcal e o rompimento com a hierarquia de gênero e com a afirmação da identidade sexual. $\mathrm{O}$ que torna a aliança entre feminismo e desconstrução muito mais difícil, mas também mais instigante e desafiadora.

${ }^{10} \mathrm{~A}$ autora rechaça o pensamento da desconstrução, argumentando que sua abordagem é insuficiente por ocultar o fato de que foi a dominação de um sexo sobre outro que produziu o dualismo que Derrida quer desconstruir. $\mathrm{Na}$ sua visão, a desconstrução estaria propondo que o homem ocupe, "desolado", a posição feminina, enquanto a mulher feminista é posta como falogocêntrica. Collin afirma que só quando o feminino ganhou valor na cultura e na sociedade - resultado, lembra ela, das lutas feministas - é que Derrida teria se declarado também feminino e proposto a recusa à lógica opositiva. Na sua crítica, Collin avalia que há um anti-feminismo no pensamento da desconstrução, como se "a instância do feminino, como modo de estar no mundo, pudesse abrir mão das mulheres" (Collin, 2004:4). 
Para ser fiel à defesa de Cornell da a aliança com a desconstrução, mostro o ponto em que a autora discorda de Derrida:

Minha diferença central em relação a Derrida está na minha insistência de que nós temos de partir da diferença sexual e, mais especificamente, temos de afirmar o feminino através da narrativa e da re-metaforização do mito. Se não permitirmos a ampla intervenção do poder de reconfiguração através do mito, da metáfora $e$, na verdade, da fantasia e da fábula, podemos potencialmente contribuir para o repúdio ao feminino. Temos de evitar a cumplicidade com os mecanismos da sociedade patriarcal que só negam o valor da mulher, ao mesmo tempo em que tentamos romper a hierarquia de gênero que se repete indefinidamente através da instalação rígida da identidade sexual (Cornell, 1999:118).

Cornell está consciente dos riscos de que sua proposição de re-metatorização do mito possa ser equivocadamente compreendida como uma volta a concepções essencialistas ou naturalistas do feminino. Ela afirma que, apesar da suspeita de Derrida de que nessa "re-metaforização" as mulheres poderiam ser mais uma vez capturadas pelas mesmas estruturas falogocêntricas que combatem, a recriação do mito do feminino seria uma estratégia de transformação do lugar da mulher a partir de novas alegorias para o feminino. Ela afirma, ainda, que sua intenção é valorizar a figura da Mulher - que ela grafa em maiúscula - e das marcas da especificidade da diferença sexual feminina, que deixaria de ser interpretada ou vista como subordinada ou complementar ao masculino.

"É uma dimensão utópica que eu sugiro como sendo necessária para afirmar o feminino" (Id.ib.:167), argumenta a autora. Cornell quer abrir a possibilidade de reconhecimento das especificidades da mulher e defende a necessidade de criação de outro lugar para o feminino, para além do determinado pela 
Diferença sexual, direitos e identidade

estrutura hierárquica e patriarcal (Id.ib.:175). Segundo ela, enquanto ser mulher for definido como uma desvantagem, mesmo que seja possível contornar essa desvantagem com a conquista de direitos, as desigualdades de gênero só serão eliminadas com o reconhecimento das mulheres com oportunidades de acesso a todos os direitos, recursos $e$ capacidades, mas não em bases de comparação com os homens.

\section{Referências bibliográficas}

BENNINGTON, Geoffrey. Entrevista com Geoffrey Bennington. In: DuQUe-ESTRADA, Paulo Cesar. (org.) Desconstrução e ética - ecos de Jacques Derrida. Rio de Janeiro, Editora PUC-Rio/Edições Loyola, 2004.

CAPUTO, John D. Dreaming of the innumerable. In: FEDER, Ellen K. et alii. (eds.) Derrida and feminism: recasting the question of woman. New York and London, Routledge, 1997.

Collin, Françoise. Le philosophe travesti ou le féminin sans les femmes. Multitudes Web, 2004 [http://multitudes.samizdat.net/Lephilosophe-travesti-ou-le.html. Consulta em 15-01-2009].

CONTINENTINO, Ana Maria. A pulsão de apropriação e a diferença sexual no pensamento de Jacques Derrida. Dissertação de mestrado em Filosofia, Pontifícia Universidade Católica do Rio de Janeiro, 2001.

CORNELl, Drucilla. Beyond Accommodation - ethical feminism, deconstruction and the law. Boston, Rowman \& Littlefield Publishers, 1999.

At the heart of freedom - feminism, sex \& equality. New Jersey, Princeton University Press, 1998.

The philosophy of the limity. New York and London, Routledge, 1992a.

. Gender, Sex, and Equivalent Rights. In: BUTLER, Judith; SCOTT, Joan. (ed.) Feminists theorize the political. New York \& London, Routledge, $1992 \mathrm{~b}$. 
DERRIDA, Jacques. Força de lei: o fundamento místico da autoridade. São Paulo, Martins Fontes, 2007. . Adeus a Emmanuel Levinas. São Paulo, Perspectiva, 2004. . Choréographies - entrevista com Christie V. McDonald. In: DERRIDA, J. Point de Suspension - Entretiens. Paris, Galilée, 1992. . At this very moment in this work here I am. In: BERNASCONY, Robert; CRITCHLEY, Simon. Re-reading Levinas. Bloomington and Indianapolis, Indiana University Press, 1991.

Différence sexuel, différence ontologique (Geschlecht I). In: DERRIDA, J. Heidegger et la question. Paris, Champs Flamarion, 1990.

ElAM, Diane. Feminism and deconstruction. New York, Routledge, 1994.

Grosz, Elizabeth. Ontology and Equivocation. In: HOLLAND, Nancy J. (org.) Feminist interpretations of Jacques Derrida. Pennsylvania, The Pennsylvania State University Press, 1997.

HeIDEGGER, Martin. Ser e tempo. vol. I. 12 ed. Petrópolis-RJ, Vozes, 2002.

INWOOD, Michael. Dicionário Heidegger. Rio de Janeiro, Zahar, 2002.

LEVINAS, Emmanuel. Entre nós: ensaios sobre a alteridade. PetrópolisRJ, Vozes, 2004.

Totalidade e infinito. Lisboa, Edições 70, 2000.

Du sacré au saint. Paris, Minuit, 1977.

RODRIGUES, Carla. Coreografias do feminino. Florianópolis, Editora Mulheres, 2009.

SCOTT, Joan W. Deconstructing equality-versus-difference: or, the uses of poststructuralist theory for feminism. Feminist Studies, vol. 14, $\mathrm{n}^{\circ}$ $1,1988$. 